\title{
RELATION OF STRUCTURE TO THE MICROHARDNESS OF HUMAN DENTIN
}

\author{
R. G. CRAIG, P. E. GEHRING, AND F. A. PEYTON \\ University of Michigan, School of Dentistry, Ann Arbor, Mich.
}

$\mathrm{T}$ HE HARDNESS of human dentin has been reported by a number of investigators using a variety of methods. Wright and Fenske ${ }^{1}$ used an abrasion method which gave macroscopic results and reported that there was no relationship between hardness and anatomic position in dentin. They also reported that dentin in the teeth of females was significantly harder than in males and that the hardness of dentin in both approached a maximum at an age of 31 to 40 years. Hodge and McKay ${ }^{2}$ used a microscratch method and stated that crown dentin was somewhat harder than root dentin, although the difference observed seems to be within the limits of experimental error. Zieger ${ }^{3}$ reported that the dentin increased in hardness with age, and Richter ${ }^{4}$ observed that dentin under areas of attrition or caries was harder than normal dentin. Likewise transparent dentin was reported by Proell and Schubert ${ }^{5}$ to be harder than normal dentin.

Previous microhardness measurements from this laboratory ${ }^{6}$ on crown dentin established an average Knoop hardness number (KHN) of 68 . It was determined that the standard deviation for dentin was $5 \mathrm{KHN}$ and that approximately 15 per cent of the hardness values had such large deviations from the average that they were considered to be outside the range of experimental error and to represent areas of different hardness. The largest variations in the hardness of dentin were observed in the transverse section just below the occlusal enamel surface and in the dentin near the dentinoenamel junction. Measurements in the latter area were generally discarded because unsymmetrical indentations were obtained as a result of uneven surfaces produced by polishing areas of different hardnesses (enamel-dentinoenamel junction-dentin). In this work it was not possible to relate hardness measurements to the histologic structure of dentin. There was some indication, however, of a relation between the histologic structure of dentin and the hardness.

The purpose of the present study is to correlate the microhardness of dentin with differences in structure. A modified Pollak trichrome staining technic ${ }^{7}$ was selected to relate these hardness values to the structure of dentin. The staining method indicated areas worthy of investigation, thereby greatly reducing the number of hardness measurements required.

This report represents the partial results of studies supported by Contract No. D-462 between the U.S. Public Health Service, National Institutes of Health, and the University of Michigan.

Received for publication Jan. 28, 1959 ; revised by authors Feb. 27, 1959. 


\section{EXPERIMENTAL}

Specimen Preparation.-Recently extracted teeth were prepared for sectioning as previously reported. ${ }^{6}$ The teeth embedded in plastic were sectioned, using a water-cooled alumina wheel, $0.33 \mathrm{~mm}$. thick. The specimens were sectioned, as shown in Fig. 1, so that alternate sections 1 to $2 \mathrm{~mm}$. and 0.1 $\mathrm{mm}$. thick were obtained. The sections were numbered and hand polished by the successive use of $400 \mathrm{~A}$ and $600 \mathrm{~A}$ Norton Tufback speed wet paper supported on a plate-glass slab. In addition, the thick sections were polished with Shamva and CRO metallographic polishes at high speeds. The thin sections were subjected to the modified Pollak trichrome staining technic. In general, areas containing large amounts of organic material were stained lark purple to blue while the more highly calcified areas were stained pink to

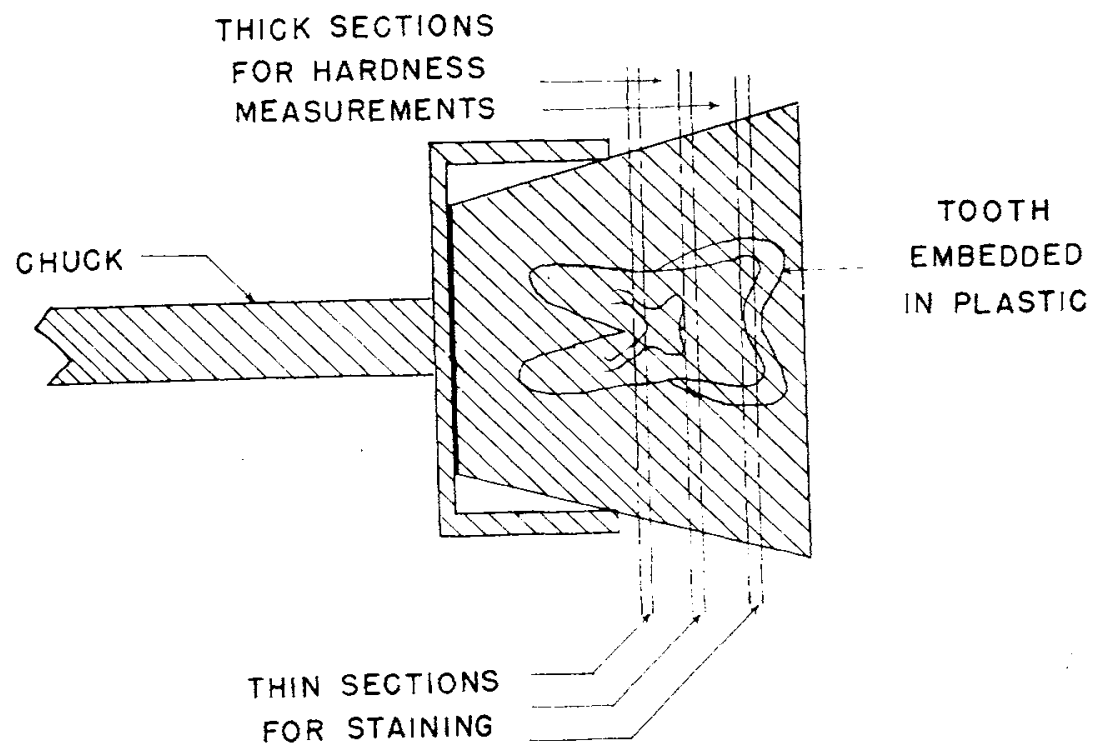

Fig. 1.- Sketch of an embedded tooth showing the positions for sectioning.

magenta (purple-red). Thus, hardness measurements could be made on the thick sections on the basis of the staining characteristics of the adjacent thin section. This procedure was necessary because the action of this stain alters the hardness of the dentin in the underlying as well as the surface layer.

Hardness Testing.-An "MO" Tukon microhardness tester with a Knoop diamond indenter was used with loads ranging from 2 to 25 grams. The measurements taken with the 10-gram load were found to show less experimental variation than those obtained with smaller loads and were considered to be more representative of microhardness values than those obtained with larger loads because of the heterogeneous nature of dentin. A normal load application cycle was used in all cases with the indenter being in contact with the specimen for 15 seconds. The ratio of the long to the short diagonal of the indentation was used as the criterion for accepting or rejecting a measurement. 
Hardness measurements were made on transverse sections of 29 mature posterior and anterior teeth. Indentations were made in areas of a polished tooth section which was of interest on the basis of the amount of stain taken up by the adjacent thin section. It was difficult to observe histologic variations on the polished dentin, and hardness measurements were meaningless if taken on polished, stained specimens.

\section{RESULTS AND DISCUSSION}

Stained transverse sections in the crown area were generally magenta in color, being darker near the center of the section and having a lightly stained ring of dentin adjacent to the dentinoenamel junction. The dimensions of this ring varied from one tooth to another but generally the ring was approximately $0.5 \mathrm{~mm}$. wide. The stained transverse sections just below the occlusal surface had a mottled appearance in the central area due to the variations in the distance from the specimen surface to the dentinoenamel junction. Sections in the center of the crown or root were sometimes mottled, the light areas indicating transparent dentin. A narrow ring around the pulp chamber in the root sections was stained magenta and denoted the predentin zone; the adjacent dentin was stained a dark red-purple, becoming more nearly magenta in color toward the cementum. The dark area appeared to represent an area where the dentin tubules were ehanging direction most rapidly. Carious areas in the dentin were also darkly stained.

Comparison of hardness measurements from one area of a tooth to another should be made within the same tooth since the hardness of dentin may vary considerably in similar areas of different teeth. Typical values for the average hardness of dentin in different transverse sections, 1 to $2 \mathrm{~mm}$. apart, are listed in Table I. Thus, for a single tooth, the average microhardness values of various sections are the same.

TABLE I

Microhardness of Dentin in Vartous Sections of a ToOth

\begin{tabular}{c|cccc}
\hline SECTION & NO. OF READINGS & AVG. KHN & MEAN DEVIATION \\
\hline 1 & 55 & 65 & \pm 7 \\
2 & 59 & 68 & \pm 9 \\
3 & 86 & 75 & \pm 9 \\
4 & 90 & 66 & \pm 9 \\
\hline
\end{tabular}

In general, hardness measurements made in the magenta-stained areas of the crown sections represented the average hardness and varied from 65 to 83 Knoop hardness numbers (KHN), while the lightly stained peripheral areas, near the dentinoenamel junction, were definitely softer, with values of 52 to 56 KHN. It should be mentioned that large differences in dentin tubule concentration were observed in crown sections but no measurable differences in microhardness were observed. Typical results obtained in crown seetions are shown in Table II. Tooth A had a high average hardness of $83 \mathrm{KHN}$ compared to teeth $\mathrm{B}, \mathrm{C}$, and $\mathrm{D}$, which had average values from 69 to $72 \mathrm{KHN}$. These latter 
values appear to more nearly represent the usual average hardness of dentin. The areas near the dentinoenamel junction in teeth $A, B, C$, and D had essentially the same hardness, the average values ranging from 52 to $56 \mathrm{KHN}$. The average deviations reported show that the average hardness values in these two areas do not overlap, but represent true differences in the hardness of the dentin. These results may be interpreted in the light of histologic information as resulting from the presence of interglobular dentin in the region of the dentinoenamel junction, the structure of which would be expected to be softer than the adjacent dentin because of the greater content of organic material. The lesser calcification of dentin in this area is also indicated by $\mathrm{x}$-ray absorption ${ }^{8,9}$ through the presence of a radiolucent zone of lower calcification. In addition, the dentin tubules may have branches in this area which might imply that the dentin near the dentinoenamel junction would be softer than the adjacent dentin.

TABLE II

Microhardness Variation of Crowa Dentin

\begin{tabular}{c|c|c|c|c|c|c}
\hline \multirow{2}{*}{ TOOTH } & \multicolumn{2}{|c|}{ CENTRAL CROWN DENTIN } & \multicolumn{3}{|c|}{ DENTIN NEAR D-F JLNCTION } \\
\cline { 2 - 7 } & $\begin{array}{c}\text { NO. OF } \\
\text { READINGS }\end{array}$ & KHN & $\begin{array}{c}\text { MEAN } \\
\text { DEVIATION }\end{array}$ & $\begin{array}{c}\text { NO. OF } \\
\text { READINGS }\end{array}$ & KHN & $\begin{array}{c}\text { MEAN } \\
\text { DEVIATION }\end{array}$ \\
\hline A & 16 & 83 & \pm 12 & 14 & 55 & \pm 7 \\
B & 4 & 72 & \pm 4 & 4 & 56 & \pm 3 \\
C & 15 & 72 & \pm 6 & 8 & 56 & \pm 4 \\
D & 8 & 69 & \pm 7 & 21 & 52 & \pm 7 \\
\hline
\end{tabular}

Richter ${ }^{4}$ reported that the erown dentin near the dentinoenamel junction was harder than the surrounding area, whereas Hodge ${ }^{10}$ published data which showed that peripheral dentin near the dentinoenamel junction had the same hardness as the adjacent dentin. These conclusions do not agree with the observations in this study that the dentin near the dentinoenamel junction is softer than the adjacent areas. Their results may be explained by the problems involved in polishing such areas and the type of equipment used to obtain the previous hardness measurements.

The microhardness measurements obtained on a typical transverse root section are represented in Fig. 2. Knoop hardness numbers of about 34 were obtained near the pulp chamber. The hardness of the dentin increased as the distance from the pulp chamber increased and a consistent value ( $65 \mathrm{KHN}$ ) was obtained about $0.5 \mathrm{~mm}$. from the pulp chamber. Inasmuch as the distance from the pulp chamber to the cementum was about $2 \mathrm{~mm}$., most of the root dentin has the same microhardness as the dentin in the center of the crown. It it not surprising that the dentin adjacent to the root canal is softer than that of the surrounding areas because of the presence of less calcified predentin. X-ray and dye absorption experiments ${ }^{11}$ have shown that the root canal dentin is more porous than the adjacent dentin, so that lower hardness values in this area would be expected.

Hodge and $\mathrm{McKay}^{2}$ reported that dentin in the root of a tooth was softer than under the crown, while Wright and Fenske ${ }^{1}$ found no relation between the hardness and position. 'The former authors' statement is true if one compares the crown dentin with the root dentin near the pulp chamber. However, 
there is no difference between the hardness of dentin in the crown or root if the root dentin farther than $0.5 \mathrm{~mm}$. from the root canal is compared with erown dentin farther than $0.5 \mathrm{~mm}$. from the dentinoenamel junction. The latter authors possibly did not observe differences in hardness in different areas of dentin because of the lack of sensitivity of the abrasion method in evaluating microhardness.

Several of the transverse crown sections contained carious areas in the dentin and a few of the transverse root sections had areas of transparent dentin. Shown in Fig. 3 is a sketch of a typical transverse crown section containing a carious area. The Knoop hardness numbers indicate that the microhardness of the carious region is very low, 19 to $34 \mathrm{KHN}$, and that the hardness of the peripheral area around the carious region is between 81 and $85 \mathrm{KHN}$, which is
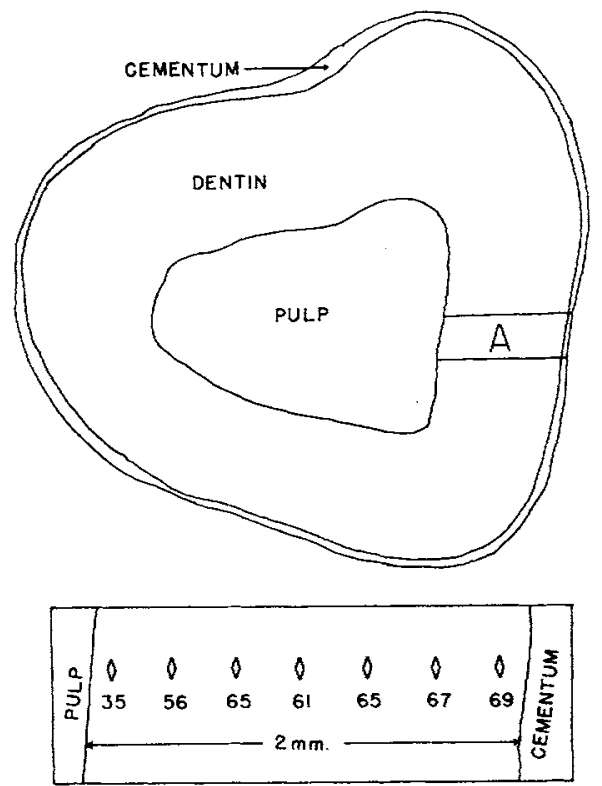

A

Fig. 2.-Microhardness variations from the pulp to the cementum in a transverse root section.

about $10 \mathrm{KHIN}$ harder than the dentin outside this peripheral caries area. Also, the hardness of the dentin near the dentinoenamel junction is lower than the surrounding areas. These measurements agree with those of Richter and Hodge and McKay ${ }^{2}$ which indieated that the dentin under areas of caries was harder than the surrounding dentin. This probably is caused by a repair mechanism which causes higher ealcification of the dentin in areas surrounding caries.

The hardness of various areas in a transverse root section containing transparent dentin is shown in Fig. 4. The transparent dentin had a Knoop hardness of about 80 compared to a value of approximately 65 in adjacent areas. This result agrees with the data of Proell and Schubert ${ }^{5}$ which showed 
that transparent dentin was harder than normal dentin, and is not surprising because transparent dentin is more completely calcified. Again, the microhardness of the dentin near the pulp chamber was low, having values of 37 to $43 \mathrm{KHN}$.

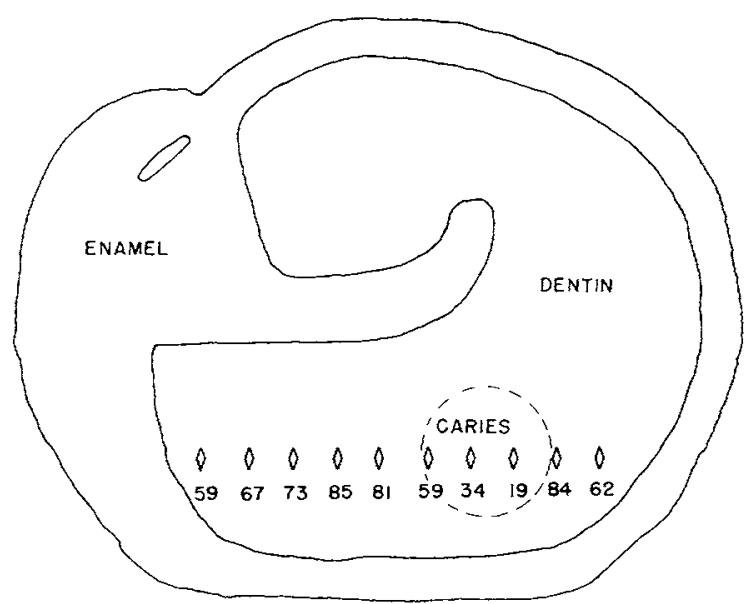

Fig. 3.-Microhardness measurements on a transverse crown section containing a carious area.

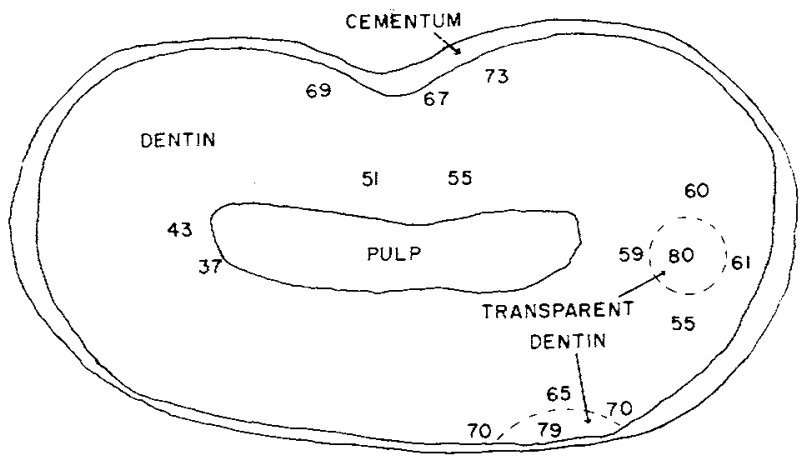

Fig. 4,-Microhardness in various areas of a transverse root section containing transparent SUMMARY AND CONCLUSIONS

A modified Pollak trichrome staining technic on polished transverse tooth sections was found useful in indicating areas in dentin that might have different microhardness values.

Microhardness measurements in transverse crown and root sections of mature, freshly extracted, human teeth showed that the hardness of dentin near the dentinoenamel junction was about $15 \mathrm{KHN}$ softer than the surrounding dentin.

The microhardness of dentin adjacent to the pulp chamber was about 30 KHN lower than the surrounding dentin.

Dentin in the center of the crown sections had the same hardness as the dentin away from the pulp chamber in the root sections. 
Dentin surrounding caries lesions had a microhardness approximately 10 KHN greater than normal dentin, whereas microhardness values at the center of the lesion were much softer.

Transparent dentin was harder than the adjacent dentin by about $10 \mathrm{KHN}$.

\section{REFERENCES}

1. Wright, H. N., and Fenske, E. L.: Factors Involved in Variability in Hardness of Tooth Struetures, J. D. Res. 17: 297, 1938.

2. Hodge, H. C., and McKay, H.: The Microhardness of Teeth, J. A. D. A. 20: 227, 1933.

3. Zieger, W.: Dissertation, Halle, 1934.

4. Richter, H.: Härteprufüng an Schmelz und Dentin. II. Über Ritz und Kugeldruckhärte der harten Zahnsubstanzen-Ein kritischer Vergleich, Ztschr. Stomatol. 29: 591, 1931.

5. Proell, F. W., and Schubert: Die Ritzhärte des Schmelzes, Ztschr. Stomatol. 26: 1047, 1928.

6. Craig, R. G., and Peyton, F. A.: The Microhardness of Enamel and Dentin, J. D. Res. 37: 661,1958 .

7. Lunt, D. A.: A Modified Pollak Trichrome Method for the Staining of Ground Sections of Teeth, Brit. D.J. 104: 17, 1958.

8. Van Huysen, G., Hodge, H. C., Warren, S. L., and Bishop, F. W.: Quantitative RoentgenRay Study of Certain Pathological Changes in Dentin, D. Cosmos 75: 729, 1933.

9. Van Huysen, G., Bale, W. F., and Hodge, H. C.: Comparative Study of the RoentgenRay Absorption Properties of Normal and Pathological Dentin, D. Cosmos 77: 146, 1935.

10. Hodge, H. C.: Microhardness Studies on Transparent Dentin, Brit. D. J. 63: 181, 1937.

11. Buchbinder, M.: Porosity of Root Canal Dentin, J. D. Res. 32: 724, 1953. 